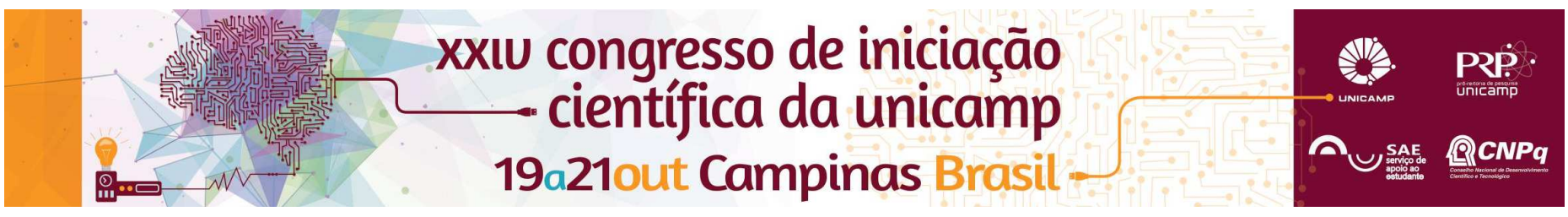

\title{
PRODUÇÃO DO CONHECIMENTO EM EDUCAÇÃO FÍSICA: impacto do sistema de pós- graduação das regiões sul e sudeste do Brasil na formação e produção de mestres e doutores que atuam nas instituições de ensino superior da região nordeste.
}

\author{
Silvio A. Sánchez Gamboa, Zuley Jhojana D. Peña, Emanuel M. Carvalho, Ana Carolina Vidal da Silva*, Claudia \\ Heleotérico Lopes*, Nayane Alves Régis*, Vanessa Gomes Marinelli*.
}

\begin{abstract}
Resumo
O projeto retoma estudos anteriores sobre a produção dos mestres e doutores, vinculados a Instituições de Ensino Superior que atuam na região nordeste, estados de Alagoas, Bahia, Pernambuco e Sergipe na área da Educação Física (1982-2004). A necessidade de atualização e ampliação do estudo para os nove estados do nordeste, incluindo Ceará, Maranhão, Paraíba, Piauí e Rio Grande do Norte e de verificar os impactos do sistema de pós-graduação de outras regiões, particularmente do Sudeste, onde se concentram $60 \%$ dos programas de pós-graduação do país e, em especial, do Estado de São Paulo que produz a maior parte das dissertações (47.1\%) e teses (72.1\%) na área, motivou este novo estudo. O projeto toma como base, dados do e-MEC, relativos às 467 IES e aos 123 cursos de EF em atividade dos nove estados da região e da CAPES relativos à produção e distribuição regional dos cursos de pósgraduação. Espera-se que os resultados gerem um banco de dados, com base na amostra regional; identifiquem redes de colaboração entre instituições e pesquisadores do nordeste na interação com outras regiões, particularmente do sudeste, caracterizem influências de autores e quadro teóricos e apresentem subsídios para a discussão da constituição do campo científico da educação física no Brasil.
\end{abstract}

\section{Palavras-chave:}

Produção do conhecimento, análise epistemológica, pesquisa em educação física.

\section{Introdução}

As atividades de apoio ao projeto temático estão vinculadas à ampliação das referências teóricas e a discussão dos resultados, particularmente às referidas à problemática da pesquisa educacional, da educação física e à análise da produção do conhecimento científico nessas áreas. A atual etapa de pesquisa, do projeto matricial, consiste na caracterização da produção científica que foi desenvolvida com o preenchimento da planilha III. Esta planilha, é um instrumento de registro e análise, e está subdivida em três momentos, conforme segue: Trazemos na planilha III-A a caracterização demográfica (identificação da população) da produção, ou seja, identificação das teses e das dissertações; Por meio da planilha III-B se dá o registro das características epistemológicas das pesquisas; E, a planilha III-C, volta-se para o registro de referências/citações destas pesquisas. $A$ atividade de pesquisa, do PIBIC-EM, para o projeto matricial, consistiu no preenchimento e na revisão da planilha III-C

\section{Resultados e Discussão}

A planilha III-C é formada por 3 colunas que identificam: a) Código do registro ou número da ficha; isto é, neste campo repetiu-se o código da planilha III-A e III-B que identificaram a tese ou dissertação; b) Análise de citação; este campo foi preenchido com as referências bibliográficas dos autores que fundamentam a interpretação - referências retiradas do texto completo. $\mathrm{O}$ preenchimento deste campo consistiu em identificar os autores mais citados no texto completo. Após essa identificação, a referência bibliográfica do autor foi copiada para este campo da planilha. A referência identificada foi transcrita e adequada com as normas atuais da ABNT independentemente da norma bibliográfica utilizado pelo autor da tese ou dissertação para construir as referências bibliográficas de sua pesquisa. c) Tipologia documental da referência; neste campo foram elaborados códigos para identificar o tipo de referência bibliográfica do autor mais citado, que foram: L-livro; C-capítulo de livro; Aartigos; T-trabalhos em eventos; D-documento histórico (fonte primária); I-documento retirado da internet; $\mathbf{N}$-norma e legislação; R-relatórios; 0-outros (fac-símiles, blog, etc).Entre os nove (9) estados da região Nordeste, que são objetos de pesquisa neste projeto, foi feita a análise da planilha III-C dos seguintes estados: Sergipe - SE; Paraíba - PB; Rio Grande do Norte - RN; Piaui - PI e Maranhão - MA. As planilhas III-C dos demais estados do Nordeste já estavam preenchida. No total foram analisadas as referências bibliográficas de 125 produções, distribuídas da seguinte maneira: SE (32); PB (23); RN (22); PI (13); MA (35).

\section{Conclusão}

A análise da planilha III-C é fundamental para a análise epistemológica porque permite indicar as principais influências teóricas que fundamentaram a interpretação das pesquisas analisadas. Além disso, permite identificar os autores mais utilizados, pelos pesquisadores, dentro da área da educação física.

\section{Agradecimentos}

FAPESP (Fundação de Amparo à Pesquisa do Estado de São Paulo). Proc. № 2012/50019-7.

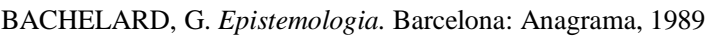
KOPNIN, P. V. A dialética como lógica e teoria do conhecimento. Rio de Janeiro: Civilização Brasileira, 1978

CHAVES-GAMBOA, M.; SÁNCHEZ GAMBOA, S. Pesquisa na Educação Física: epistemologias, escola e formação profissional. Maceió: edUFAL, 2009 